\title{
Socio-demographic Characteristics of Patients with Tuberculosis Spine in Bangladesh
} \author{
Md. Shafiul Alam ${ }^{1}$, Md. Abdus Salam
Md. Saiful Islam
Mayseer Farzana
}

\begin{abstract}
${ }^{1}$ Assistant Professor, Department of Gamma Knife Neurosurgery, National Institute of Neurosciences \& Hospital, Dhaka, Bangladesh; ${ }^{2}$ Associate Professor, Department of Neuro-trauma Surgery, National Institute of Neurosciences \& Hospital, Dhaka, Bangladesh; ${ }^{3}$ Consultant (Radiology \& Imaging), Popular Diagnostic Centre, Mirpur, Dhaka, Bangladesh; ${ }^{4}$ Assistant Professor, Department of Physiology, Shaheed M. Monsur Ali Medical College, Sirajgonj, Bangladesh; ${ }^{5}$ Assistant Professor, Department of Microbiology, Shaheed M. Monsur Ali Medical College, Sirajgonj, Bangladesh
\end{abstract}

[Received: 1 January 2015; Accepted: 15 July2015; Published: 1 June 2016]

Abstract
Background: Spinal tuberculosis is more frequently reported in developing countries. Objective: The
purpose of the present study was to see the socio-demographic characteristics of spinal tuberculosis
patients. Methodology: This study was carried out in the Department of Neurosurgery, Dhaka Medical
College Hospital during the period of January 2002 to December 2004 to elucidate the effectiveness of
surgical and conservative treatment of the tuberculosis of the spine. For this purpose, a total number of 50
consecutive cases admitted during the study period with tuberculosis of the spine supported by
investigations were included in this study. Result: The mean age of the patients was 25.4 years and ranged
from 7 years to 68 years. The highest incidence of tuberculosis of the spine was found in age group
between 11 to 20 years and $70 \%$ of the patients were under 30 years of age. Incidence of tuberculosis of
this spine was more in male (62\%) in comparison to female (3 8\%) with a male female ratio of 1.63:1. In
this study most of the patients came from low class society (66\%) followed by middle class (28\%) and
high class (6\%) respectively. Conclusion: Spinal TB more frequently occurs among the young age group
with a male predominance. [Bangladesh Journal of Infectious Diseases 2016;3(1):3-5]
Keywords: Spinal TB; sociodemographic; epidemiology
[How to Cite this article: Alam MS, Salam MA, Farzana T, Newaz ASMR, Islam MA. Socio-demographic Characteristics of
Patients with Tuberculosis Spine in Bangladesh. Bangladesh J Infect Dis 2016;3(1):3-5]
Corresponding author: Dr. Md. Shafiul Alam, Assistant Professor, Department of Gamma Knife Neurosurgery, National
Institute of Neurosciences \& Hospital, Dhaka, Bangladesh; Email: dr_chapal@ @otmail.com; Cell no.: +8801711567358
Conflict of Interest: Authors have declared no conflict of interest.
Contributions to authors: MSA and MAS have contributed from protocol preparation to manuscript writing as well as in data
collection. TF, MAI \& ASMRN have prepared and have revised the manuscript.

\section{Introduction}

Tuberculosis of the spine is one of the oldest diseases afflicting humans ${ }^{1}$. Evidences of spinal tuberculosis have been found in Egyptian mummies dating back to $2400 \mathrm{BC}^{2}$. The descriptions in
Rigveda, Atharvaveda and Charak Samhita are the oldest known texts in the world literature relating to this disease ${ }^{3}$. The association of paraplegia and kyphotic deformity of the spine was first noticed by Sir Percival Pott ${ }^{4}$. 
Tuberculosis was a leading cause of mortality in the beginning of the twentieth century. Improvement in the socio-economic status led to a major decline in the prevalence even before the introduction of antituberculous drugs ${ }^{5}$. However, it continues to be a major public health problem in developing countries. Malnutrition, poor sanitation and exanthematous fever are the factors contributing to the spread of the disease ${ }^{6}$. In the United States, there has been a steady increase in the prevalence of pulmonary as well as extrapulmonary tuberculosis. This is largely due to impairment of immune system by the human immunodeficiency virus leading to reactivation of latent infection and a likelihood of progression to active disease ${ }^{7}$.

In Bangladesh spinal tuberculosis is predominantly a disease of the young, the usual age of presentation being the first three decades of life ${ }^{8}$. Reports from developed countries indicate a much older patient population, the median age at diagnosis being sixtyone years. In most series, the disease has been found to affect males and females in equal proportions ${ }^{9}$. Therefore, this present study was undertaken to see the socio-demographic characteristics of spinal tuberculosis patients.

\section{Methodology}

This was a cross sectional study carried out in the Department of Neurosurgery at Dhaka Medical College Hospital, Dhaka, Bangladesh from January 2003 to December 2004 for a period of 2(two) years. The study was purposive. All patients who were admitted with the diagnosis of spinal tuberculosis were included in the study. Clinically suspected patients of TB spine and supported by investigation findings were included as study population. Patients with history of spinal injury were excluded from this study. Details sociodemographic characteristics were prepared by the researcher with key variables like age and sex of the patient, Socio economic status. The collected data was edited and analyzed SPSS 16.0 computer programme. Prior to commencement of this study, the research protocol was approved by local ethic committee.

\section{Results}

A total number of 50 patients were recruited for this study after fulfilling the inclusion and exclusion criteria. In this study, 50 cases of tuberculosis of the spine showed the age range from 7 years to 68 years with the highest incidence in the first three decades $(70 \%)$ of life. The peak incidence was in the second decade (34\%). The mean age was 25.4 years with $\mathrm{SD} \pm 18.65$ years (Table 1$)$.

Table 1: Distribution of patients by age $(n=50)$

\begin{tabular}{|l|c|c|}
\hline Age Group & Frequency & Percent \\
\hline 0 to 10 Years & 4 & 8.0 \\
\hline 11 to 20 Years & 17 & 34.0 \\
\hline 21 to 30 Years & 14 & 28.0 \\
\hline 31 to 40 Years & 7 & 14.0 \\
\hline 41 to 50 Years & 5 & 10.0 \\
\hline 51 to 60 Years & 2 & 4.0 \\
\hline 61 to 70 Years & 1 & 2.0 \\
\hline Total & $\mathbf{5 0}$ & $\mathbf{1 0 0 . 0}$ \\
\hline
\end{tabular}

The sex distribution showed male preponderance. Among 50 patients $31(62 \%)$ were male and $19(38 \%)$ were female. Male female ratio was 1.63:1 (Table 2).

Table 2: Distribution of patients by sex $(n=50)$

\begin{tabular}{|l|c|c|}
\hline Sex & Frequency & Percent \\
\hline Male & 31 & 62.0 \\
\hline Female & 19 & 38.0 \\
\hline Total & $\mathbf{5 0}$ & $\mathbf{1 0 0 . 0}$ \\
\hline
\end{tabular}

Regarding the socioeconomic status $33(66 \%)$ patients came from low class society, 14 (28\%) came from middle class society and $3(6 \%)$ came from upper class society (Table 3).

Table 3: Distribution of patients by Socioeconomic status $(n=50)$

\begin{tabular}{|l|c|c|}
\hline S-E status & Frequency & Percent \\
\hline Upper class & 3 & 6 \\
\hline Middle class & 14 & 28 \\
\hline Low class & 33 & 66 \\
\hline Total & $\mathbf{5 0}$ & $\mathbf{1 0 0 . 0}$ \\
\hline
\end{tabular}

\section{Discussion}

The world has nearly 30 million people suffering from tuberculosis ${ }^{10}$. Of all the patients with tuberculosis 1 to 3 percent has involvement of the skeletal system. Spinal tuberculosis is the commonest form of skeletal tuberculosis and it constitutes about $50.0 \%{ }^{11}$. Topographically, spinal tuberculosis constitutes about half the cases of skeletal tuberculosis. 
The dorsal spine is involved in half the cases of spinal tuberculosis. The disease is always secondary to a primary visceral focus which may be in the lungs, lymph nodes or kidneys ${ }^{12}$. Extrapulmonary tuberculosis is more common in children than in adults, the commonest site being the superficial lymph nodes. A minimum time lag of 2 to 3 years is present between the development of primary focus and manifestation of the disease in the spine ${ }^{11}$. The bacteria may reach the spine through the arterial circulation or the Batson's plexus of veins. Initially, two contiguous vertebral bodies are involved due to a common vascular supply. Destruction of vertebral bodes compromises the nutrition of the intervertebral disc and leads to progressive disc destruction and vertebral collapse ${ }^{12}$.

Spinal tuberculosis may occur at any age but most common during first three decades of life ${ }^{13}$. In this series age was 25.4 years and ranged from 7 years to 68 years. The highest incidence was in first three decades $(70 \%)$ of life. In another study it has been shown the highest incidence in first three decades of life and it is $73 \%{ }^{14}$. Currently there is a tendency of involvement of adult age group particularly in the developed countries due to high incidence of AIDS, intravenous drug abuse and other causes of immune suppression ${ }^{15}$.

The disease is equally distributed among both sexes ${ }^{16}$. But this series showed male preponderance. The male female ratio was $1.63: 1$. This may be due to male people are more active and expose to external environment in Bangladesh. Tuberculosis is a disease of low socio-economic group. Malnutrition, illiteracy and poor hygienic conditions are responsible for this ${ }^{17}$. This present study also showed that most of the patients came from low class society. It indicates that people require more awareness about nutrition and hygiene to prevent tuberculosis ${ }^{18}$.

\section{Conclusion}

In conclusion spinal $\mathrm{TB}$ is more common among the young age group. There is a male predominance. Furthermore, the low socioeconomic condition people are frequently affected by spinal TB.

\section{References}

1. Akman S, Sirvanci M, Talu U, Gogus A, Hamzaoglu A. Magnetic resonance imaging of tuberculous spondylitis. Orthopedics. 2003;26(1):69-73

2. Alici E, Akçali Ö, Tatari H, Günal İ. Effect of preoperative chemotherapy on the outcome of surgical treatment of vertebral tuberculosis: retrospective analysis of 434 cases. Archives of Orthopedic and Trauma Surgery. 2001;121(1):65-6

3. Alwali AA. Spinal brace in tuberculosis of spine. Saudi Medical Journal 2002;23(12):1483-8.

4. Andronikou S, Jadwat S, Douis H. Patterns of disease on MRI in 53 children with tuberculous spondylitis and the role of gadolinium. Pediatric radiology. 2002;32(11):798805

5. Arct MW. Operative treatment of tuberculosis of the spine in old people. J Bone Joint Surg Am. 1968 Mar 1;50(2):255-67.

6. Bhojraj S, Nene A. Lumbar and lumbosacral tuberculous spondylodiscitis in adults. Bone \& Joint Journal. 2002 May 1;84(4):530-4.

7. Capener N. Vertebral tuberculosis and paraplegia. Bone \& Joint Journal. 1967;49(4):605-6.

8. Cauthen Je. Lumber spine surgery. Williams and Wilkins, $1^{\text {st }}$ Edition 1983

9. Cleveland M, Bosworth DM. The pathology of tuberculosis of the spine. J Bone Joint Surg Am. 1942;24(3):527-46

10. Dinç H, Ahmetoğlu A, Baykal S, Sari A, Sayil O, Gümele HR. Image-guided Percutaneous Drainage of Tuberculous Iliopsoas and Spondylodiskitic Abscesses: Midterm Results 1. Radiology 2002;225(2):353-8.

11. Evarts Mc. Surgery of the musculo-skeletal system. Churchill Living stone, $2^{\text {nd }}$ Edition. 1990.

12. Upadhyay SS, Saji MJ, Yau AC. Duration of antituberculosis chemotherapy in conjunction with radical surgery in the management of spinal tuberculosis. Spine. 1996 Aug 15;21(16):1898-903.

13. Oga M, Arizono T, Takasita M, Sugioka Y. Evaluation of the Risk of Instrumentation as a Foreign Body in Spinal Tuberculosis: Clinical and Biologic Study. Spine. 1993;18(13):1890-4.

14. Hodgson AR, Yau AC. Anterior surgical approaches to the spinal column. Recent Advances in Orthopaedics. Baltimore, Williams \& Wilkins. 1964:289-323.

15. Jain AK. Tuberculosis of the spine. Bone \& Joint Journal. 2010;92(7):905-13

16. Hodgson AR, Skinsnes OK, Leong CY. The pathogenesis of Pott's paraplegia. JBJS. 1967;49(6):1147-56.

17. Jalleh RD, Kuppusamy I, Mahayiddin AA, Yaacob MF, Yusuf NA, Mokhtar A. Spinal tuberculosis: a five-year review of cases at the National Tuberculosis Centre. The Medical journal of Malaysia. 1991;46(3):269-73.

18. Kohli SB. Radical surgical approach to spinal tuberculosis. J Bone Joint Surg Br. 1967;49(4):668-73. 